\title{
Study on flexural performance of prestressed glulam continuous beams under control influence
}

\author{
Lidan Mei ${ }^{1}$, Nan Guo ${ }^{1 *} \mathbb{0}$, Ling Li ${ }^{1}$, Hongliang Zuo ${ }^{1}$ and Yan Zhao ${ }^{2}$
}

\begin{abstract}
Traditional glulam beam connection mode has a weak ability to transfer bending moment, leading to insufficient joint stiffness and mostly in the form of simply supported beams. To make full use of material strength, a novel prestressed glulam continuous beam was proposed. On this basis, this paper put forward a new method to further improve the mechanical performance of the beams by controlling prestress. According to the estimated ultimate loads of the beams, six different control range values were formulated, and 12 continuous beams were tested for flexural performance. The effects of prestressing control on the failure modes, ultimate load capacity, and load versus deformation relationships of the glulam continuous beams were analyzed. The test results indicated that the flexural performance of the beams with prestressed control was significantly improved compared to the uncontrolled beams, the ultimate load was enhanced by $13.60 \%-45.11 \%$, and the average steel wire stress at failure was increased from $70 \%$ of the designed tensile strength to $94 \%$. Combined with the finite element analysis (FEA), the reasonable control range of the prestressed control continuous beams was $18 \%-30 \%$ of the estimated ultimate load. The research in this paper can provide references for the theoretical analysis and engineering application of similar structures.
\end{abstract}

Keywords: Prestressed glulam continuous beams, Flexural performance, Experimental study, FEA, Control ranges

\section{Introduction}

Timber has significant advantages such as pollution-free, low energy consumption, and recyclability. Glulam is the most common engineering wood product in timber structure, reduces the impact of natural timber defects by processing natural timber, which can improve its strength and stiffness [1-9]. As one of the prominent flexural members in timber structure buildings, the glulam beam is of great significance to the safety of the whole structure. However, when the glulam beam was flexural, the tensile zone of the beam would be prone to brittle failure, and its compressive strength to be not fully used [10-15]. Furthermore, the length of the glulam beam does not

\footnotetext{
*Correspondence: snowguonan@163.com

${ }^{1}$ College of Civil Engineering, Northeast Forestry University,

Harbin 150040, China

Full list of author information is available at the end of the article
}

meet the requirements of the continuous beam due to the limit of raw material size and processing technology. And the current bolt connection has a weak ability to transfer bending moment, resulting in insufficient joint stiffness. Thus glulam beams are mostly simply supported beams [16-19]. To take full advantage of material properties and enrich structural forms, the author of this paper based on the previously proposed prestressed glulam simply supported beams, and then exploited the prestressed glulam continuous beam through a new set of connection apparatuses, as shown in Fig. 1a [20, 21]. The continuous beam combined two glulam beams through the new connection apparatus. In this case, the prestress can enhance the connection tightness between the two beams so this study regarded this connection method as a rigid connection realized by the apparatus and prestress. This paper aims to solve the problem that the application of prestressing is limited by the tensile strength of the top
Springer Open
C The Author(s) 2021. Open Access This article is licensed under a Creative Commons Attribution 4.0 International License, which permits use, sharing, adaptation, distribution and reproduction in any medium or format, as long as you give appropriate credit to the original author(s) and the source, provide a link to the Creative Commons licence, and indicate if changes were made. The images or other third party material in this article are included in the article's Creative Commons licence, unless indicated otherwise in a credit line to the material. If material is not included in the article's Creative Commons licence and your intended use is not permitted by statutory regulation or exceeds the permitted use, you will need to obtain permission directly from the copyright holder. To view a copy of this licence, visit http://creativecommons.org/licenses/by/4.0/. 
a

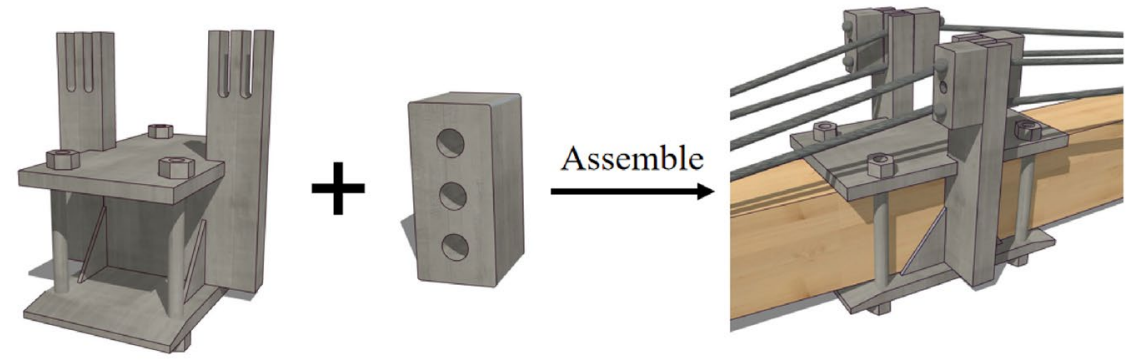

b

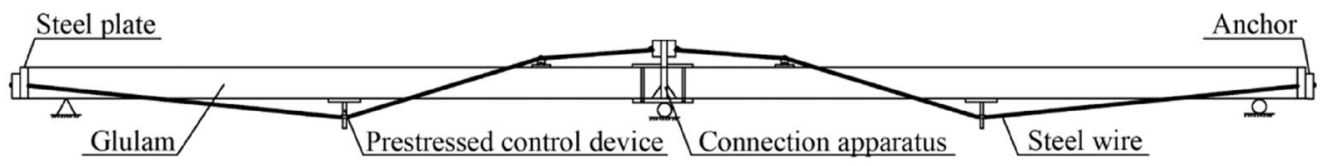

c

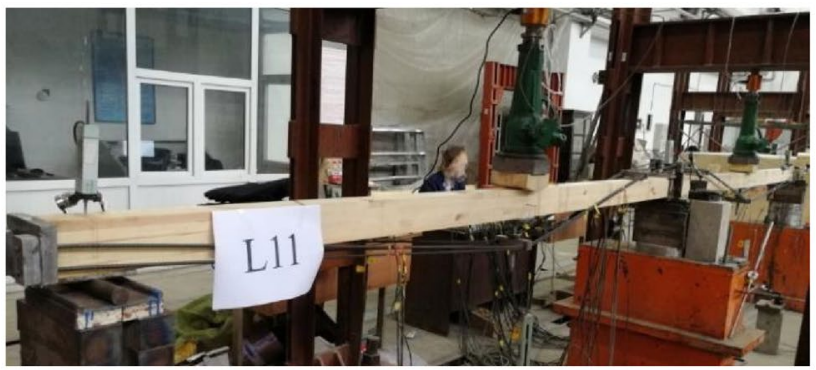

Fig. 1 Prestressed glulam continuous beam. a Details of connection apparatus; $\mathbf{b}$ details of the specimen; $\mathbf{c}$ photo of the specimen

of glulam beams. Thus, a new concept of prestressing control is proposed, namely, the beam is applied a certain range of load before prestressing, and then adjust the deflection of the beam to the state of the load is not applied. That is of great academic value and engineering significance to study the influence of the control range on the flexural performance of the prestressed glulam continuous beams.

More recently, some researchers have studied the combination of different materials and glulam to improve its strength. Uzel et al. [22] studied the flexural behaviors of glulam beams retrofitted with aluminum, fiberglass, and steel wire nets at the lamination surfaces. It was found that steel wire reinforcement nets can significantly increase the ultimate load-bearing capacity. Ribeiro et al. [23] proposed a concept of laminated wood composite with fiberglass and demonstrated the beneficial effect of the proposed strengthening solutions in terms of resistance and ductility. Zuo et al. [24] compared experiments on glulam beams reinforced by tapping screws. The results confirmed the importance of the reinforcements in enhancing ultimate load and stiffness. Yang et al. [25] proposed the reinforcement method of pasting steel plates or adding screws at the bottom of the glulam beam. Results showed that the bending performance of glulam beams was improved.

To effectively enhance the flexural behavior of glulam beams and use the advantages of various materials, researchers applied the methods for strengthening glulam beams with prestressed materials. Anshari et al. [26] tested glulam beams were strengthened by inserting compressed wood blocks into the pre-cut rectangular holes from the top of the beam. Based on the moisturedependent swelling nature of the compressed wood, a pre-camber was produced in the mid-span of the beam. A comparison with the beam without prestressing indicated that the initial stiffness and load-carrying capacity of the pre-stressed beam were increased significantly. Yang et al. [27] examined the reinforcing in flexure of glulam beams using bonded-in carbon fiber reinforced polymer bars. They found that the flexural capacity of prestressed and reinforced (bottom prestressed and top reinforced) beams increased up to $131 \%$. McConnell et al. [28] conducted a series of four-point bending tests under post-tensioned glulam beams and indicated the flexural strength and stiffness increased for post-tensioned timbers. Previous studies have provided references for this paper from the use of different materials, prestressing 
methods, and key factors affecting the mechanical performance of prestressed glulam beams.

This paper will examine the flexural behavior of 12 prestressed glulam continuous beams by considering the effect of control ranges. Failure modes, ultimate load capacity, and load versus deformation relationships will be investigated. And finite element analysis (FEA) will be conducted to obtain the optimally control range.

\section{Materials and methods}

\section{Specimens and materials}

In this paper, the prestressed glulam continuous beam was composed of glulam, high-strength steel wires, and steel components (Fig. 1). The steel components were comprised of connection apparatuses, prestressed control devices, steel plates, and anchors. The glulam with dimensions $3070 \mathrm{~mm}$ (length, $L) \times 80 \mathrm{~mm}$ (breadth, b) $\times 100 \mathrm{~mm}$ (height, $h$ ) was glued by five layers of $20 \mathrm{~mm}$ thick spruce planks. All specimens were set with four low-relaxation prestressed steel wires, which $12.9 \mathrm{~mm}$ in diameter.

Based on the previous work [29], the service load of the beam was about $30 \%$ of its ultimate load. Therefore, according to the previous research results and theoretical analysis, the ultimate load of the test beam was estimated during the research. Then, five control values were selected near $30 \%$ of the estimated ultimate load to explore the influence of different prestressed control

Table 1 Groups and information of specimens

\begin{tabular}{lll}
\hline Group & Beam code & $\begin{array}{l}\text { Control } \\
\text { range } \\
(\%)^{\mathbf{a}}\end{array}$ \\
\hline 1 & L01, L02 & 0 \\
2 & L11, L12 & 18 \\
3 & L21, L22 & 24 \\
4 & L31, L32 & 30 \\
5 & $L 41$, L42 & 36 \\
6 & $L 51$, L52 & 42 \\
\hline
\end{tabular}

${ }^{a}$ The percentage of the initial load to the estimated ultimate load of the beam ranges on the flexural performance of the beams. Overall, six groups and 12 specimens were manufactured and tested. The groups and information of specimens are represented in Table 1.

All material properties were tested following the Chinese Standard GB/T50329-2012 [30] and GBT228.1-2010 [31]. The detailed mechanical properties of specimens as shown in Table 2.

\section{Assembly procedure}

As shown in Fig. 2, the assembly process of specimens included five steps: (1) the positioning lines of steel components and joints were drawn on the glulam beams; (2) prestressed control devices were attached to the corresponding positioning lines by adhesives, which were set for a while until the adhesive was completely solidified; (3) steel wires were cut and prepared in the length of design requirements, passed through anchors, and the ends of the steel wires anchoring by a machine; (4) after the glulam beams were jointed by connection apparatuses, the anchors at the ends of the steel wires were put into the slot of steel plates at the beam ends, and the steel wires were put into the prestressed control devices; (5) the initial load was applied to the beams by jacks, nuts in the prestressed control devices were tightened. Meanwhile, the jacks were unloaded to control the initial load within $1 \mathrm{kN}$, and the deflection change was measured by the linear variable differential transformers (LVDTs) in the mid-span. When the reading values of LVDTs were not zero, which indicated that the length of the steel wires did not reach the required standard, it was necessary to add the plates between the anchors and the steel plates or cut the steel wires again.

\section{Measurement layout}

To measure the strain state of the glulam and the steel wires, the $100 \mathrm{~mm} \times 3 \mathrm{~mm}$ strain gauges were pasted at the beam top, bottom and side of the mid-span. Since ribbed steel wires were used in this test, the steel wire surfaces at $L / 4$ distance from the beams' support points were polished by an angle grinder, so it was convenient

Table 2 Material properties

\begin{tabular}{llcc}
\hline Material & Category & Average (N/mm $\mathbf{m}^{\mathbf{2}}$ & $\mathbf{C o V}_{(\mathbf{\%})^{\mathbf{a}}}$ \\
\hline Spruce & Compression strength parallel to grain & 38.67 & 6.151 \\
& Modulus of elasticity in compression compression & $8.301 \times 10^{3}$ & 4.630 \\
& Tensile strength parallel to grain & 81.32 & 6.184 \\
Steel wire & Modulus of elasticity in tensile & $9.750 \times 10^{3}$ & 6.420 \\
& Tensile strength & $1.640 \times 10^{3}$ & 0.3541 \\
\hline
\end{tabular}

${ }^{\mathrm{a}}$ Coefficient of variation 


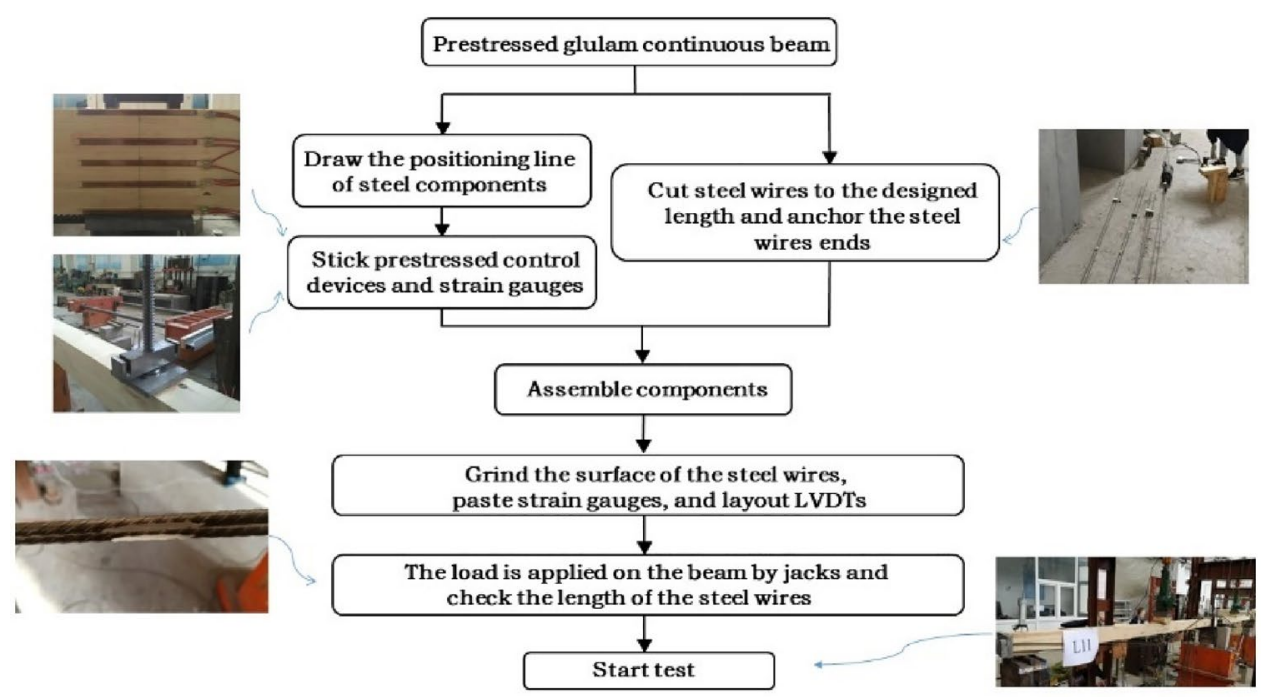

Fig. 2 Assembly process

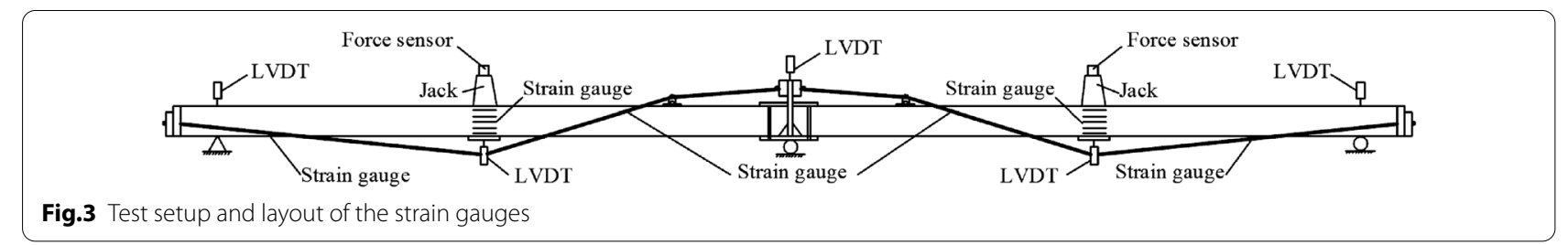

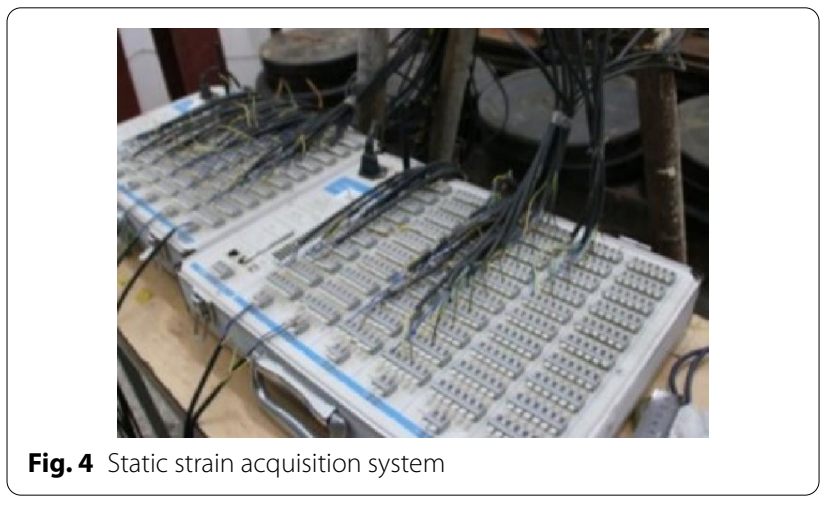

to paste the $2 \mathrm{~mm} \times 3 \mathrm{~mm}$ strain gauges. To monitor the deflection of the beams, three LVDTs with a range of $50 \mathrm{~mm}$ were placed at its support, and an LVDT with a range of $150 \mathrm{~mm}$ was set in the mid-span (Fig. 3). JM3813 static strain acquisition systems (Yangzhou Jingming Technology Co., Ltd, China) were applied to collect the strain and deflection measurements, as shown in Fig. 4.

\section{Loading mechanism}

1. Preliminary load. According to the previous test results and theoretical analysis, the estimated ultimate load of the specimens was determined to be 30 $\mathrm{kN}$. The pre-loading with $6 \%-12 \%-6 \%$ of the estimated ultimate load as a loading cycle, there were five cycles in total, and finally was restored to $0 \%$. The experimental data did not include the above work results. The purpose of pre-loading is to eliminate the initial gaps between the components of the prestressed continuous beams.

2. Control of prestressing. The initial load $(F)$ to be applied is $0 \%, 18 \%, 24 \%, 30 \%, 36 \%$ and $42 \%$ of the estimated ultimate load. The specimens generated deflection after the initial load was applied. After that, some researchers adjusted the deflection of the beam by twisting the prestressed control devices at the beam bottom and generated upward forces $\left(F^{\prime}\right)$ to increase the pressure at the top of the beam. And then other researchers needed to unload the jacks simultaneously. In this process, the pressure sensor and DH3818 static strain acquisition system (Yangzhou Jingming Technology Co., Ltd, China) were 
used to monitor the internal force changes, and the changes were controlled within $1 \mathrm{kN}$. The prestressed control process is shown in Fig. 5.

3. Failure loading. The loading process started from the control range value, and the load increment of each level was $6 \%$ of the estimated ultimate load. When the loading reached $72 \%$ of the estimated ultimate load, the displacement control loading was used. In the stage of displacement control loading, the average value of the beam deflection increment under four levels of load between 48 and $72 \%$ of the estimated ultimate load was calculated. And this average value was taken as the displacement increment of each level of this stage until the beam failed.

\section{Principles for determining failure and ultimate loads}

According to the failure determination of wood components based on the Chinese Standard GB/ T50329-2012 [30], as well as the failure determination of the reinforced concrete elements based on the Chinese Standard GB/T50152-2012 [32], and combined with the actual situation of this test, the failure signs of the glulam beams can be summarized as the following three situations. When one of them appears in the trial, it can be determined that the beam failed:

1. The tensile strain of the prestressed steel wire reaches 0.01 .

2. Apparent cracks appear in the tension zone of the glulam beam, or significant wrinkles occur in the compression zone of the glulam beam. Also, the load-deflection curve decreases with loading.

3. The prestressed steel wire is broken, or the anchor device at the beam-end fails.
In the step loading test, the measured values of the ultimate load are determined according to the following principles:

1. When a failure sign appears during the loading process, the load value of the previous grade is taken as the measured value of the ultimate load in the test.

2. When the failure sign appears during the sustained loading process, the average value of the load of this grade and the load of the previous stage are taken as the measured value of the ultimate load in the test.

3. When the failure sign appears after the sustained loading is completed, the load value of this grade is taken as the measured value of the ultimate load in the test.

4. When the load-deflection curve decreases with loading, the peak point of the curve is used as the measured value of the ultimate load in the test.

\section{Experimental results and discussion \\ Failure modes}

For all the specimens, the experimental phenomena can be classified into three main failure modes: compression failure at the beam top, tension failure of the weak areas between laminates, and instability failure. The specific contents are shown as follows:

\section{Compression failure at the beam top}

As the load increased, the deflection of the specimens increased gradually. When the load reached $90 \%-95 \%$ of the beams' ultimate load, wood knots or weak areas on the top of the beams appeared wrinkles because the glulam reached the compressive strength. With the continuous application of the load, the load no longer increased and showed a downward trend, each wrinkle began to extend and developed gradually. Finally, the beams were snapped off due to the tearing of the laminate at the

a

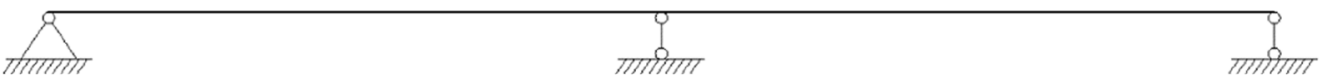

b

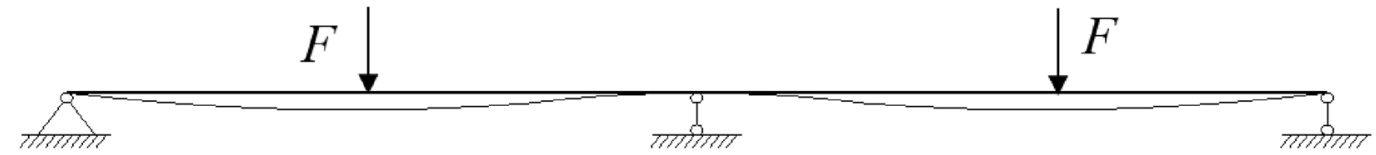

c

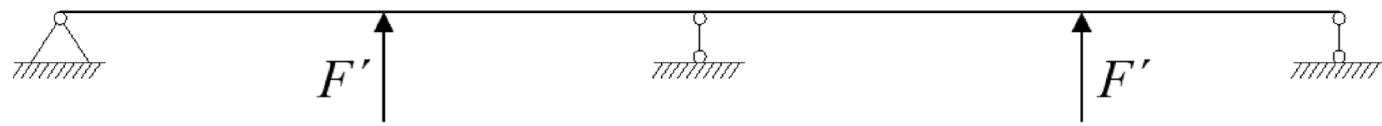

Fig. 5 Prestressed control process. a Before the initial load applied; $\mathbf{b}$ after the initial load applied; c control completed 
wrinkles, and the beams were damaged. The typical failure modes of the specimens are shown in Fig. 6.

\section{Tension failure of the weak areas between laminates}

At the initial stage of loading, the deflection raised with the increase of load, and there was no apparent damage to the specimens. When the loading value reached $83 \%-$ $89 \%$ of the peak load of the beams, the laminates were subjected to compression parallel to grain, which product tensile stress perpendicular to grain, and finally the tensile strength was insufficient. The longitudinal cracks first appeared at the weak areas of the laminates. They continued to extend to the beam ends, which significantly increased the deflection of the beams and reduced the load, and finally led to the decrease of the bearing capacity of the beams or the failure to continue loading, as shown in Fig. 7.

\section{Instability failure}

At the initial stage of loading, the deflection continued to increase, and there was no apparent damage to the beams. When the load was close to the peak load of the beams, bolt bars in the prestressed control devices gradually deflected out of the plane, which was due to the error in the cutting length of the steel wires, resulting in force distribution on the steel wires unevenly. Or because of the defects in the contact part of the glulam and steel plates along the beam width direction, it was not enough to uniformly resist the pressure exerted on the glulam by the bolt bars. When the glulam was damaged by local compression, the bolt bars would be deflected out of the plane. With the continuous loading, the load showed a downward trend, the fracture occurred at the weak areas of the laminate, and longitudinal tear occurred. Then the beams were broken at the loading position, and the beams were overturned as a whole, as shown in Fig. 8 .

When the continuous beam was damaged, only one span was fully damaged, and the other span was not completely damaged or had no sign of fail. The incomplete damaged span was not representative, so only the failure mode of the completely damaged span was counted, as shown in Table 3.

Figure 9 presents the distribution of failure modes for all specimens. When the control range was small, the tensile stress of the steel wires was low. Compared with the stress produced by the compression at the beam end, the stress caused by the bending moment was more obvious in the glulam, so the compression failure at the top
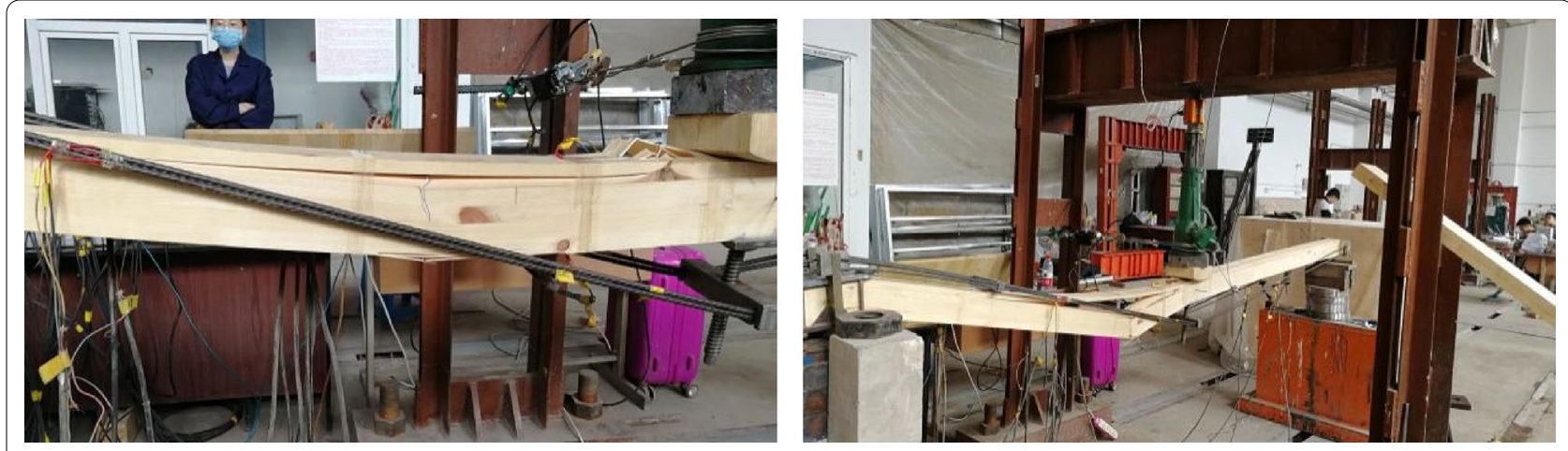

Fig. 6 Compression failure of the beam top
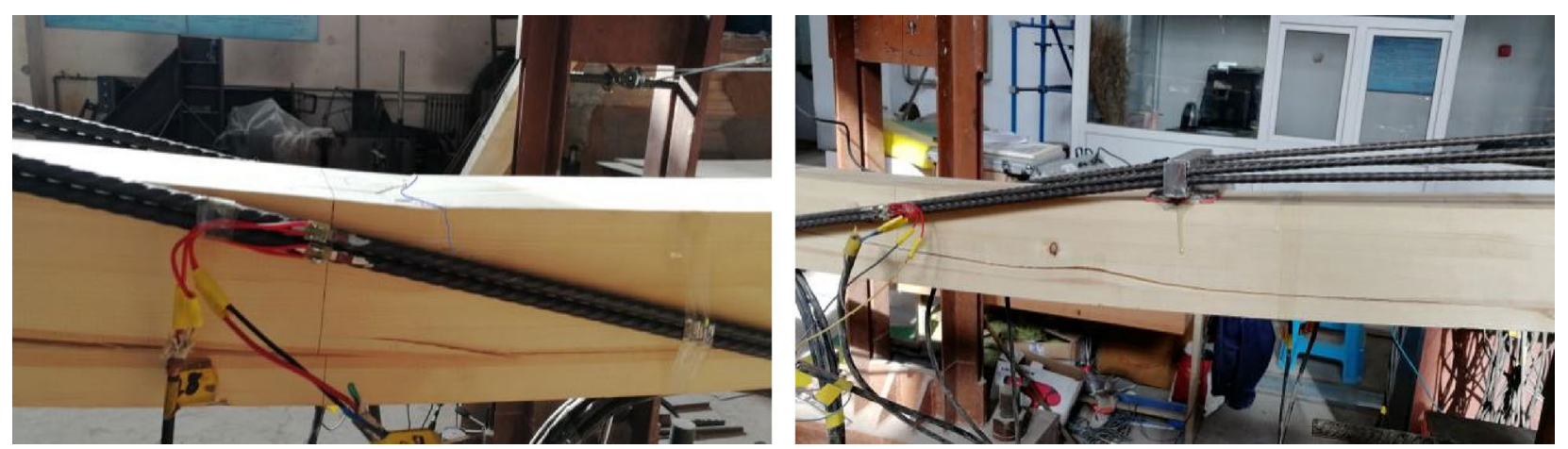

Fig. 7 Tension failure of the weak areas between laminates 

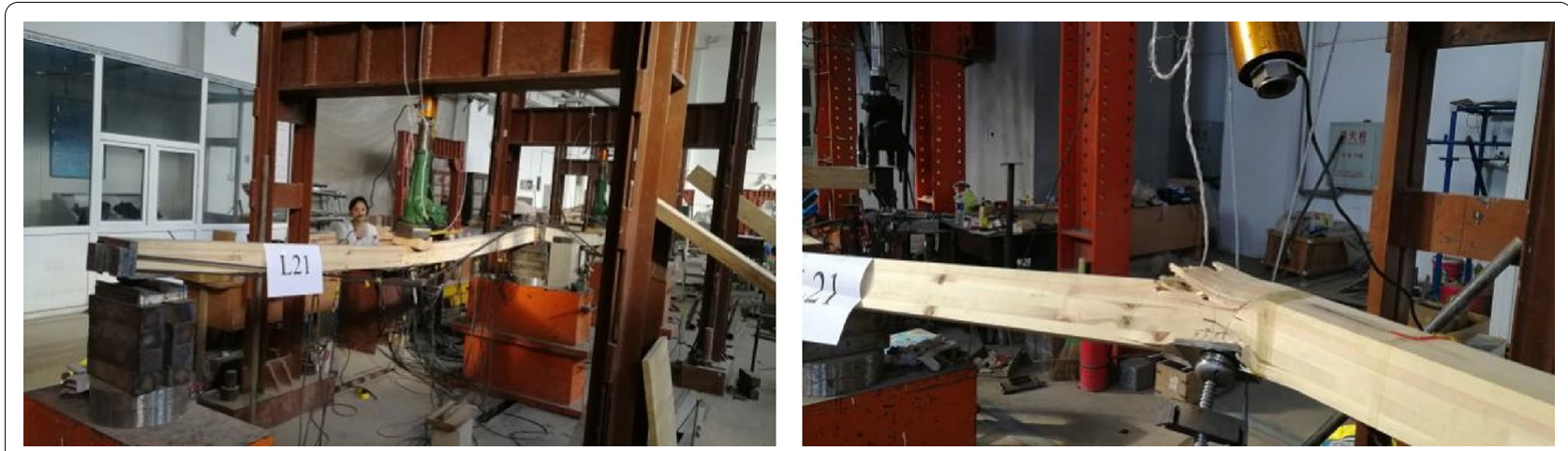

Fig. 8 Instability failure

Table 3 Failure modes of specimens

\begin{tabular}{lll}
\hline Control range & Beam code & Failure mode \\
\hline 0 & $L 01$ & Compression \\
& $L 02$ & Compression \\
$18 \%$ & $L 11$ & Compression \\
& $L 12$ & Compression \\
$24 \%$ & $L 21$ & Instability \\
& $L 22$ & Compression \\
$30 \%$ & $L 31$ & Compression \\
& $L 32$ & Tension \\
$36 \%$ & $L 41$ & Tension \\
& $L 42$ & Compression \\
$42 \%$ & $L 51$ & Tension \\
& $L 52$ & Instability \\
\hline
\end{tabular}

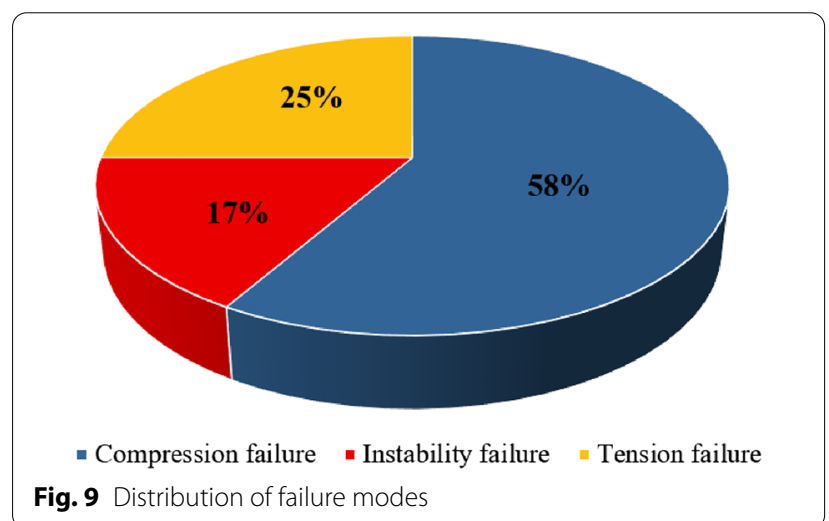

of the glulam was more likely to occur. When the control range was large, the tensile stress of the steel wires and the compressive stress of the corresponding glulam part was also enormous. At this point, in the part of the glulam, the pressure generated by the beam end compressed was more significantly higher than the stress caused by
Table 4 Ultimate load of specimens

\begin{tabular}{lllll}
\hline $\begin{array}{l}\text { Control } \\
\text { range (\%) }\end{array}$ & Beam code & $\begin{array}{l}\text { Ultimate } \\
\text { load (kN) }\end{array}$ & Average (kN) & $\begin{array}{l}\text { Increased } \\
\text { ratio (\%) }\end{array}$ \\
\hline 0 & $L 01$ & 29.15 & 30.08 & - \\
& $L 02$ & 31.01 & & \\
18 & $L 11$ & 33.02 & 34.17 & 13.60 \\
& $L 12$ & 35.32 & & \\
24 & $L 21$ & 40.44 & 40.77 & 35.54 \\
& $L 22$ & 41.10 & & \\
30 & $L 31$ & 45.42 & 44.04 & 46.41 \\
& $L 32$ & 42.66 & & \\
36 & $L 41$ & 44.23 & 43.19 & 43.58 \\
& $L 42$ & 42.15 & & \\
42 & $L 51$ & 44.70 & 43.65 & 45.11 \\
& $L 52$ & 42.60 & & \\
\hline
\end{tabular}

the bending moment, so its failure mode was characterized by eccentric compression members with the minor bending moment, such as out-of-plane instability, laminate tearing (similar to compression splitting), etc.

\section{Ultimate load}

As shown in Table 4 and Fig. 10, compared with the beams without prestressed control, the ultimate load of the prestressed beams increased between $13.60 \%$ and $45.11 \%$. Before the control range value reached $30 \%$, the ultimate load of the beams rose linearly with the increase of the control range. After reaching 30\%, the peak load basically remained stable due to the compressive strength of the glulam part had been fully used when the control range value was $30 \%$. On this basis, if the control range continues to increase, the glulam part may occur outof-plane instability or laminate tearing failure due to the excessive compressive stress, which limits the further improvement of bearing capacity. Overall, it demonstrates that there is a reasonable range of prestressed 


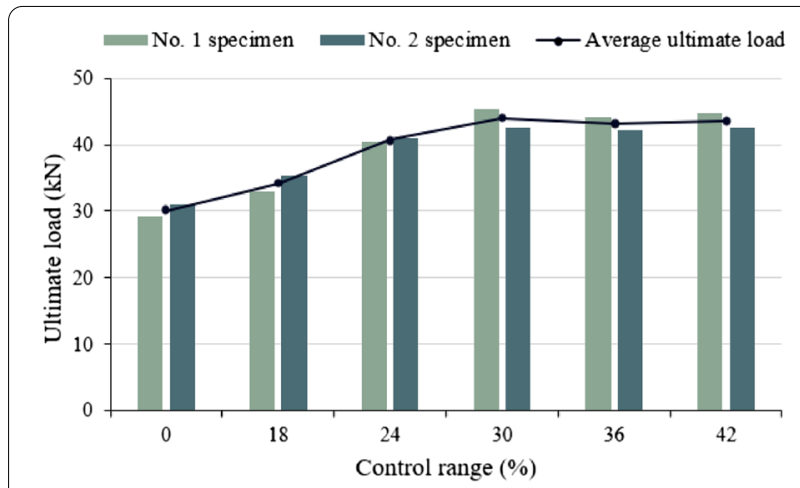

Fig. 10 Tendency graph of ultimate load

control, not the higher the control range, the better the effect.

\section{Load-deflection relationships}

Among the two beams of each group under the same working conditions, a representative one was chosen to show the load-deflection behavior, as shown in Fig. 11.

From the results plotted in Fig. 11, it can be observed that the curves of the left and right spans of the prestressed control beams were slightly different, but the general trend was the same. On the one hand, from the initial stage of loading to the final failure, with the increase of the control range, the slope of the curve and the ultimate load showed a rising trend, namely, enhancing the control range value can effectively improve stiffness and the peak load of the beams. On the other hand, the ultimate deflection decreased as the control range increased, which due to the deformation capacity of the prestressed glulam beams mainly depended on the compression yield of the glulam. When the control range was large, the beams often occurred out-of-plane instability and laminate tearing failure, so the ultimate deflection decreased. Even so, the ultimate deflection of the beams after control was still more than 1/50 of the span. By referring to the management of other structures on the ultimate deflection of the beams, the prestressed glulam continuous beam after control can still meet the design requirements.

\section{Stress at the failure of prestressed steel wires}

To study the prestressed steel wire stress under the ultimate load, experimental results are tabulated in Table 5 and plotted in Fig. 12. It can be found that the stress of the prestressed steel wires raised as the control range increased when the specimens failed. When the control range value increased to $42 \%$, the average value of steel wires' failure stress reached $94 \%$ of the design value of tensile strength $f_{\mathrm{py}}$, indicating that the steel wire strength had been effectively used.

Table 5 Failure stress of steel wires

\begin{tabular}{|c|c|c|c|}
\hline \multirow{2}{*}{$\begin{array}{l}\text { Control range } \\
\text { (\%) }\end{array}$} & \multirow[t]{2}{*}{ Beam code } & \multicolumn{2}{|c|}{ Stress $\left(\mathrm{N} / \mathrm{mm}^{2}\right)$} \\
\hline & & Test value & Average \\
\hline \multirow[t]{2}{*}{0} & L01 & 798.2 & 772.6 \\
\hline & L02 & 747.0 & \\
\hline \multirow[t]{2}{*}{18} & L11 & 911.8 & 908.4 \\
\hline & L12 & 904.9 & \\
\hline \multirow[t]{2}{*}{24} & L21 & 897.9 & 872.4 \\
\hline & L22 & 846.9 & \\
\hline \multirow[t]{2}{*}{30} & L31 & 974.4 & 964.0 \\
\hline & L32 & 953.7 & \\
\hline \multirow[t]{2}{*}{36} & $\llcorner 41$ & 953.4 & 976.2 \\
\hline & $\llcorner 42$ & 999.0 & \\
\hline \multirow[t]{2}{*}{42} & L51 & 1063 & 1031 \\
\hline & L52 & 999.4 & \\
\hline
\end{tabular}

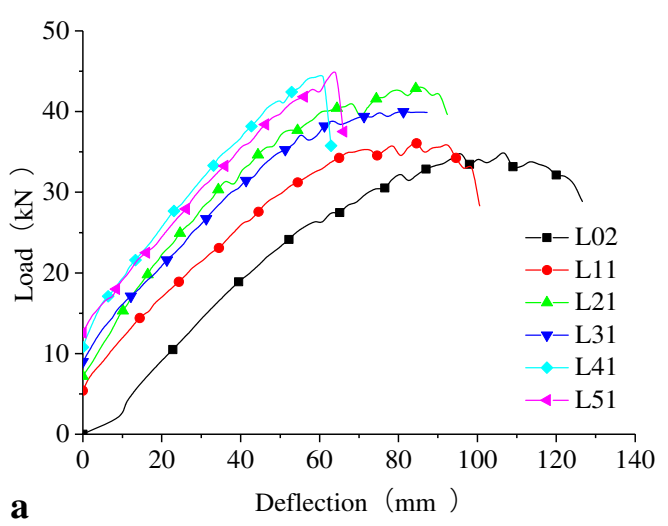

a

Fig. 11 Load-deflection curves of all the specimens. a Left span of specimens; $\boldsymbol{b}$ Right span of specimens

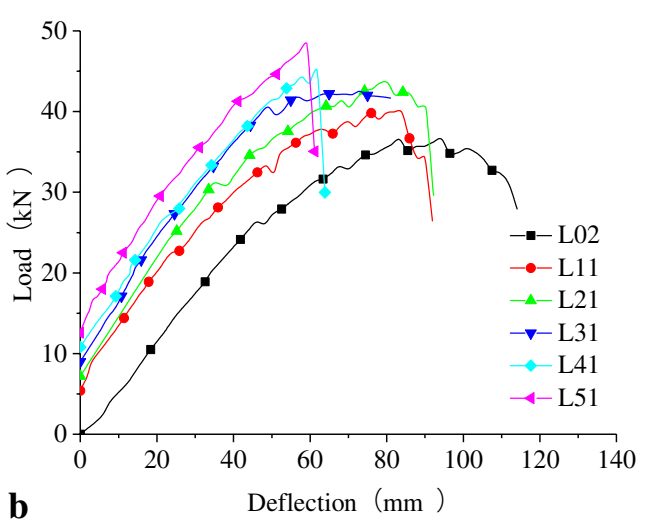




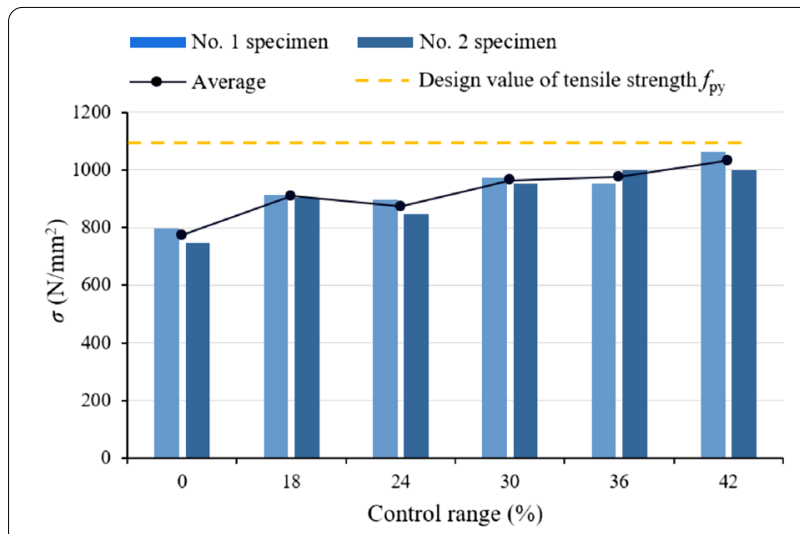

Fig. 12 Tendency graph of steel wire stress

Besides, compared with other specimens, when the control range value was $24 \%$, the stress value of the steel wires was abnormal and relatively low. The reason is that L21 occurred the instability failure at the loading position of the right span beam and L22 had the large wood knot at the laminate, which led to the unconventional material failure, and the material strength was not fully used. Therefore, the stress of the steel wires was abnormal when the control range value was $24 \%$.

\section{Load-strain relationships}

Typical load-strain curves are illustrated in Fig. 13, in which 1-5 represents laminates numbers (see Fig. 14). And the negative $\mathrm{X}$-axis indicates that the material is under compression; the positive $\mathrm{X}$-axis demonstrates that the material is under tension; the Y-axis represents the load; the different curves show the mechanical behavior of the laminate and wire.

As the prestress control range grew, the tensile stress of the steel wires was raised, the neutral axis of the glulam section moved down, and the compressive zone enlarged. Moreover, due to the compressive part of the glulam increased gradually, its strain development of the glulam tended to be slow with the increase of the load, and the strain distribution was more uniform. It is evident that the prestress control can make the internal force redistribution of the glulam (Fig. 15), thus achieved make full use of the material properties and improve the bearing capacity of the beams.

\section{Finite element analysis}

To further study the mechanical performance of the beams with more control range values and give a reasonable range of prestressing control, a 3D finite element (FE) model was established using ABAQUS (engineering analysis software, version 6.14) to simulate the prestressed glulam continuous beams with different control range values.

\section{Finite element model}

The prestressed glulam continuous beam was composed of glulam, steel wires, and steel components. To avoid the influence of irregular mesh generation on the analysis, thus the regular simplified model was used for each element. The prestressed steel wires were defined as lines, and other components were defined as solid elements. The FE model is shown in Fig. 16.

Three steps were set up in this model, namely the initial step, prestressed control, and concentrated force. In the initial step, the constraints and boundary conditions of each component were created. The specific operation method is as follows: reference points were set at the top position of the middle of each span of the continuous beam, the reference points and the top cushion blocks of the mid-span beam were constrained by coupling. Similarly, reference points were set at the beam supports, constrained coupling with the support cushion blocks. The steel components and the glulam connecting parts were constrained by tying. Prestressing control used bolt load to offset the deflection caused by the initial load. Applying a downward concentrated force to the middle of each span of the continuous beam, the magnitude of the force was the specimens' peak load of each group. All the components (except steel wires) were meshed separately using C3D8 elements. The steel wires were meshed by the B31 elements.

\section{Constitutive model of materials}

The deformation of the steel components was considered in the design; as the stiffness of the steel components met the requirements, the elastic deformation of the steel components was not considered in the FEA, and its elastic modulus was $2.0 \times 10^{5} \mathrm{~N} / \mathrm{mm}^{2}$. According to the material testing, the elastic modulus of the prestressed steel wires was $1.92 \times 10^{5} \mathrm{~N} / \mathrm{mm}^{2}$. The behavior of glulam as an orthotropic material within the elastic range is expressed by

$$
\sigma_{i}=D_{i j} \varepsilon_{j} \quad \forall \quad i, j \in\{1,2, \ldots, 6\},
$$

where $\varepsilon_{j}$ is the strain vector, $\sigma_{i}$ the stress vector, and $D_{i j}$ the stiffness matrix of the orthotropic material, as shown in Table 6.

\section{Reasonable control range}

To validate the model for the prestressed glulam continuous beam, the FE models were compared with the experimental results in this study. Owing to the limited space of this paper, only the load-deflection curves of some beams are shown in Fig. 17. 


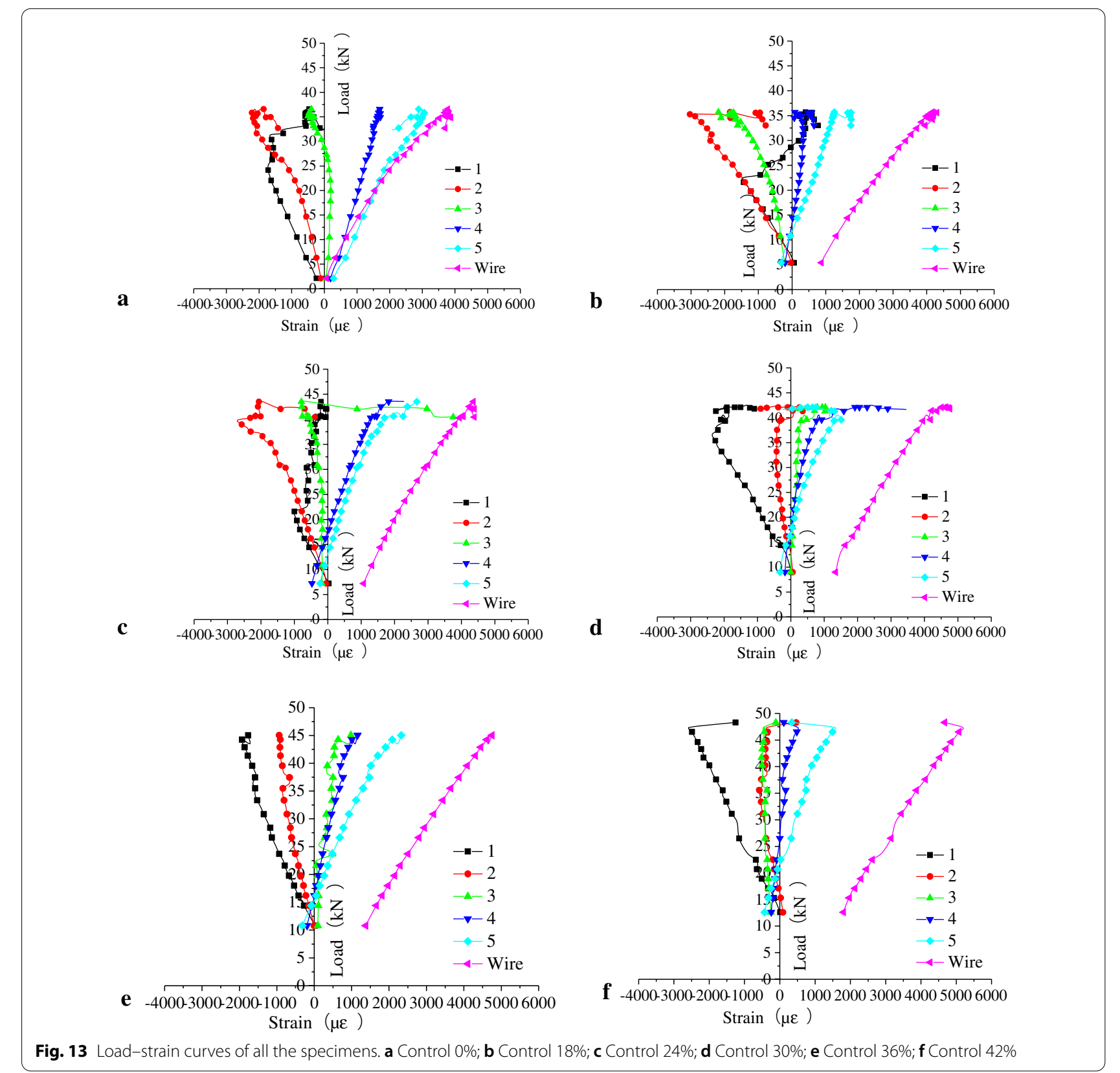

It can be concluded from Fig. 17 that the maximum error between the FE models and the experimental results was $37.6 \%$, which indicates that the models can simulate and analyze the beams more accurately, so the control range values can be expanded through the ABAQUS. To study the reasonable range of prestressed control and compare with the results of the specimens, $6 \%$ and $12 \%$ of the control range value were added in the FEA. The specific grouping and the FEA results are shown in Table 7. Because of the limited space of this paper, to present the stress distribution of the glulam beam clearly, one span of the continuous beam (control range value is 12\%) was selected in Fig. 18. On the left side of the figure is the end of the continuous beam, and the right side of the figure is the part of the glulam beam inserted into the connection apparatus, and Fig. 18 shows the distribution of compressive stress and tensile stress parallel to grain of the beam. Due to the support at the connection, an upward support reaction force was generated. According to the deformation geometric compatibility equations and the equilibrium conditions, the bending moment distribution of the continuous beam was obtained by theoretical calculation 


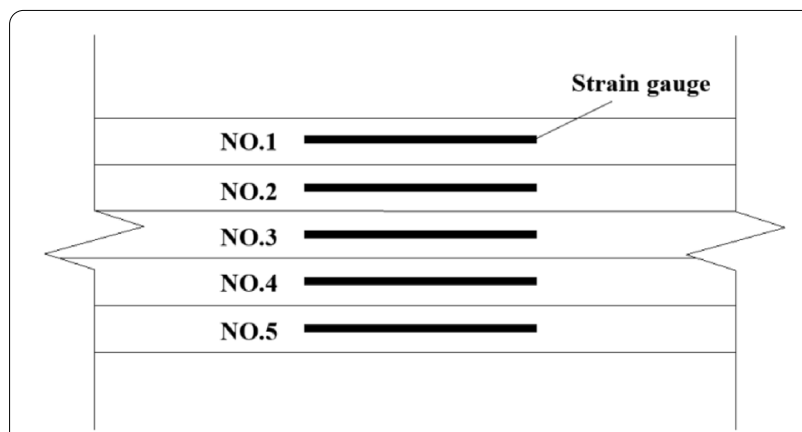

Fig. 14 The serial number of Strain gauges placement along the beam at the mid-span

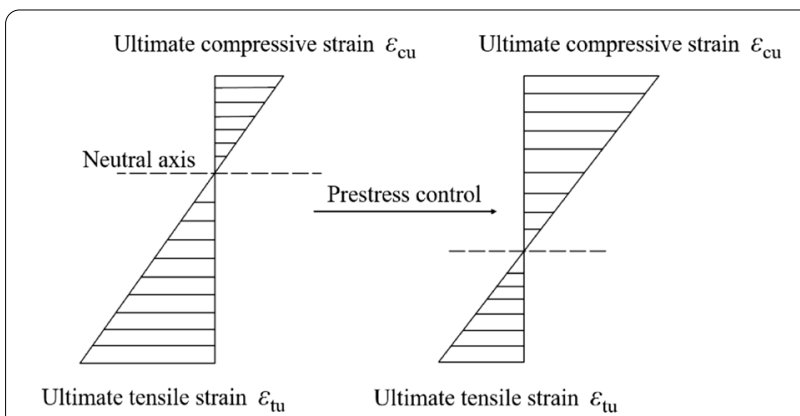

Fig. 15 The strain distribution of the beam at the mid-span

as shown in Fig. 19. It can be seen that the top of the beam at the connection bore high tensile stress, which was the same as the simulation result.

Furthermore, the connection apparatus in Fig. 1a was made of steel, and its elastic modulus is higher than that of glulam, which means that the steel connection apparatus had the greater stiffness and can withstand the higher load. Although the middle support of the continuous beam was subjected to large tensile stress during the loading process, which was mainly carried by the steel, and the stress shared to the end of the glulam beam was relatively small. Meanwhile, according to the experimental phenomena and results, it can be known that the final failure of the continuous beam was caused by the midspan region. Therefore, it can be proved that the connection joint in this test can bear large tensile stress and avoid failure from occurring at the joint.

\section{Stress of steel wires}

As shown in Table 7, when the prestressed control was completed and the beam was damaged, the stress of steel wires of all beams was higher than the test results, the maximum deviation was about $17.5 \%$. It is caused by uncontrollable factors in the test process, including different defects of glulam and uneven force applied by researchers during loading. In the FEA, glulam was an ideal material without defects, the material was fully used, so the simulation values were higher than the experimental values (Fig. 20).

\section{Ultimate load}

As illustrated in Table 7, the ultimate load of the beams can be significantly increased by prestressing control. As the control range value of the beams changed from 6 to $42 \%$, the ultimate bearing capacity of the beam was increased by $8.86 \%-45.74 \%$. A comparison between FEA and test results of the ultimate load is plotted in Fig. 21, the development trend of the curves was approximately the same, which indicates that the FEA results were relatively

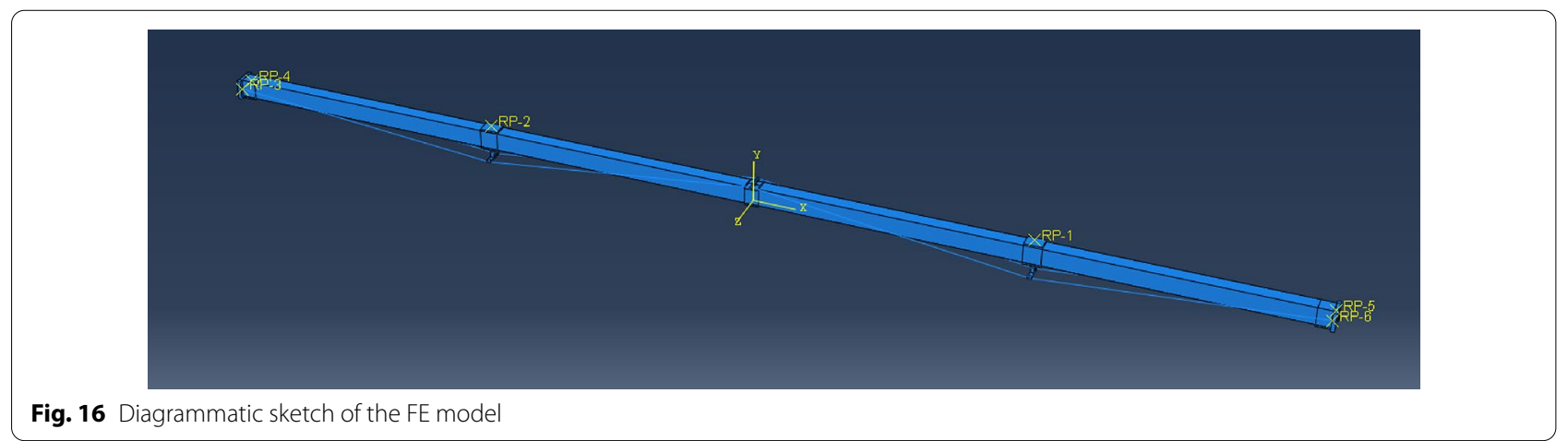

Table 6 Parameters in stiffness matrix of the glulam (Unit: N/mm²)

\begin{tabular}{|c|c|c|c|c|c|c|c|c|}
\hline$D_{11}$ & $D_{22}$ & $D_{33}$ & $D_{44}$ & $D_{55}$ & $D_{66}$ & $G_{12}$ & $G_{13}$ & $G_{23}$ \\
\hline $9.118 \times 10^{3}$ & $3.443 \times 10^{2}$ & $3.406 \times 10^{2}$ & $4.981 \times 10^{2}$ & $4.981 \times 10^{2}$ & $1.494 \times 10^{2}$ & $1.905 \times 10^{2}$ & $2.420 \times 10^{2}$ & $2.006 \times 10^{2}$ \\
\hline
\end{tabular}



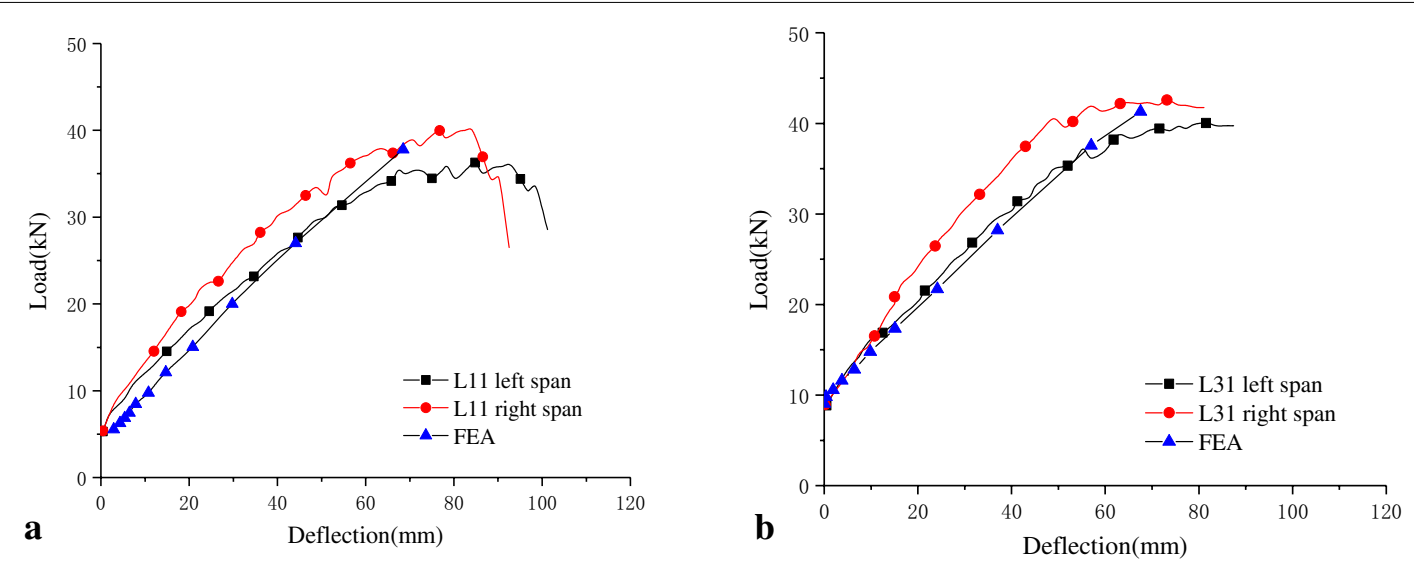

Fig. 17 Comparison of FEA and test results. a Control 18\%; b Control 30\%

Table 7 FEA results

\begin{tabular}{|c|c|c|c|c|c|}
\hline \multirow{2}{*}{$\begin{array}{l}\text { Beam } \\
\text { code }\end{array}$} & \multirow{2}{*}{$\begin{array}{l}\text { Control } \\
\text { range } \\
(\%)\end{array}$} & \multicolumn{2}{|c|}{ Continuous beam } & \multicolumn{2}{|l|}{ Steel wires } \\
\hline & & $\begin{array}{l}\text { Ultimate } \\
\text { load (kN) }\end{array}$ & $\begin{array}{l}\text { Increased } \\
\text { ratio (\%) }\end{array}$ & $\begin{array}{l}\text { Control } \\
\text { stress }^{\mathrm{a}}(\mathrm{N} / \\
\mathrm{mm}^{2} \text { ) }\end{array}$ & $\begin{array}{l}\text { Failure } \\
\text { stress (N/ } \\
\mathrm{mm}^{2} \text { ) }\end{array}$ \\
\hline SL1 & 0 & 28.90 & - & 0 & 850.0 \\
\hline SL2 & 6 & 31.46 & 8.860 & 73.00 & 902.0 \\
\hline SL3 & 12 & 34.51 & 19.41 & 159.0 & 950.0 \\
\hline SL4 & 18 & 37.25 & 28.89 & 251.0 & 985.0 \\
\hline SL5 & 24 & 40.82 & 41.24 & 332.0 & 1025 \\
\hline SL6 & 30 & 42.12 & 45.74 & 414.0 & 1060 \\
\hline SL7 & 36 & 40.26 & 39.31 & 473.0 & 1085 \\
\hline SL8 & 42 & 38.35 & 32.70 & 555.0 & 1105 \\
\hline
\end{tabular}

${ }^{a}$ The stress of the steel wires when the prestressed control is completed

consistent with the test results. However, when the control range increased from 36 to $42 \%$, the ultimate load of the test beams basically remained unchanged, which was slightly different from the FEA results. That is because the control range values were high, out-of-plane instability and laminate tearing occurred in the test beams.

Furthermore, when the control range was small, the compressive stress of the beam top cannot reach the compressive strength of the glulam, the stress of steel wires and glulam increased, thus the ultimate load of the beams was improved. As the control range expanded to a certain value, the compressive stress at the top of the beam arrived at the compressive strength of the materials, and its bearing capacity was decreased. Combined with the test results and FEA, when the control range value was less than $18 \%$, the steel wire strength was not fully used and the bearing capacity of the beam was limited. When the control range value was more than $30 \%$, the bearing capacity of the beam would not be increased. Therefore, the reasonable control range of the prestressed glulam continuous beam was about $18 \%-30 \%$ of the ultimate load.

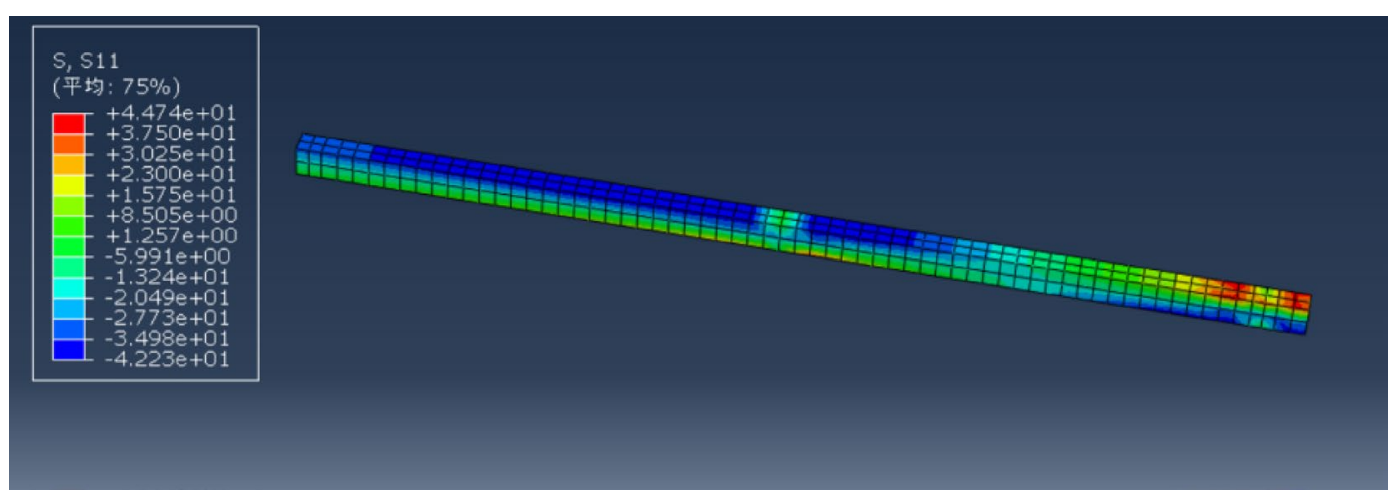

Fig. 18 Diagrammatic sketch of the stress distribution 


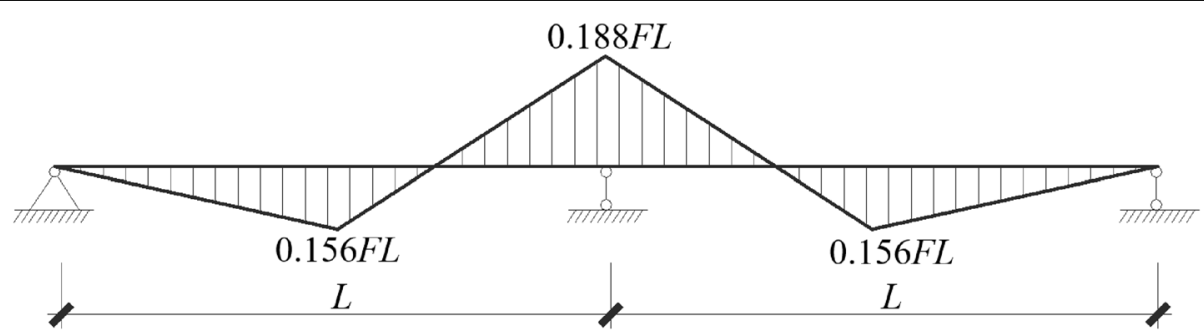

Fig. 19 Moment distribution of the continuous beam

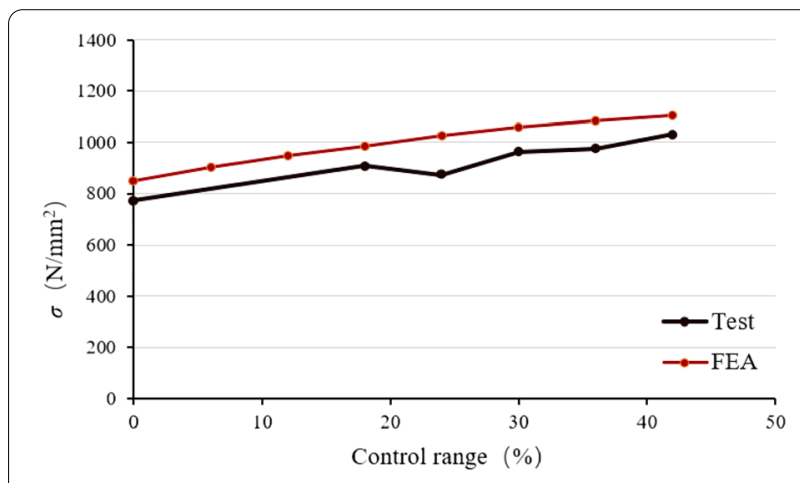

Fig. 20 Comparison between FEA and test results of the steel wire stress

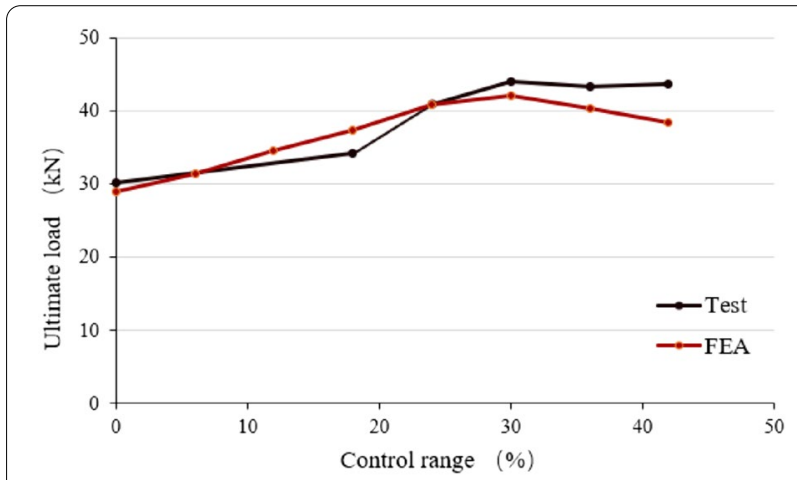

Fig. 21 Comparison between FEA and test results of the ultimate load

\section{Conclusions}

1. For the prestressed glulam continuous beams, there were three main failure modes, which were compression failure at the top of the beam, tension failure of the weak areas between laminates, and instability failure. The probability of three kinds of failure was $58 \%, 25 \%$ and $17 \%$, respectively. When the control range was small, the glulam continuous beams mainly occurred compression failure. Increasing the control range, the possibility of instability failure and laminate tearing failure increased.

2. Before the control range value reached $30 \%$, the ultimate load of the beam increased linearly as the control range increased. After that reached 30\%, the ultimate load basically remained unchanged.

3. The stress of prestressed steel wires was raised with the increase of the control range. The control range value grown up from 0 to $42 \%$, stress at the failure of the prestressed steel wires reached $94 \%$ of the design value of tensile strength $f_{\mathrm{py}}$, which demonstrates that the strength of steel wire had been fully used.

4. Based on the test and FEA results, the control range value was low than $18 \%$, the bearing capacity of the beam was limited, and the steel wire strength was not fully used. When the control range value was more than $30 \%$, the bearing capacity of the beam would not be increased. Therefore, the reasonable control range of the prestressed glulam continuous beams was about $18 \%-30 \%$ of its estimated ultimate load.

\section{Abbreviations}

FEA: Finite element analysis; CoV: Coefficient of variation; FE: Finite element.

\section{Acknowledgements}

The authors express our gratitude to Mingtao Wu for his assistance with this study.

\section{Authors' contributions}

LM wrote the draft of this manuscript. NG formulated and designed the experiments. $\mathrm{LL}$ and $\mathrm{HZ}$ analyzed the data. $Y Z$ reviewed and edited the manuscript. All authors read and approved the final manuscript.

\section{Funding}

This project is supported by the Natural Science Foundation of Heilongjiang Province (LH2019E005), the Natural Science Foundation of Heilongjiang Province (LH2020E009), and the Natural Science Foundation of Fujian Province (2020J01402)

\section{Availability of data and materials}

The datasets used and/or analyzed during the current study are available from the corresponding author on reasonable request. 


\section{Declarations}

\section{Competing interests}

The authors declare that they have no competing interests.

\section{Author details}

${ }^{1}$ College of Civil Engineering, Northeast Forestry University, Harbin 150040, China. ${ }^{2}$ College of Civil Engineering and Architecture, Wuyi University, Wuyishan 354300, China.

Received: 18 March 2021 Accepted: 7 July 2021

Published online: 14 July 2021

\section{References}

1. Elnaklah R, Walker I, Natarajan S (2021) Moving to a green building: Indoor environment quality, thermal comfort and health. Build ment 191:107592

2. He M, Luo J, Tao D, Li Z, Sun YL, He GR (2020) Rotational behavior of bolted glulam beam-to-column connections with knee brace. Eng Struct 207:110251

3. Issa CA, Kmeid Z (2005) Advanced wood engineering: glulam beams. Constr Build Mater 19(2):99-106

4. Song JW, Chen CJ, Zhu SZ, Zhu MW, Dai JQ, Ray U, Li YJ, Kuang YD, Li YF, Quispe N, Yao YG, Gong A, Leiste UH, Bruck HA, Zhu JY, Vellore A, Li H, Minus ML, Jia Z, Martini A, Li T, Hu LB (2018) Processing bulk natural wood into a high-performance structural material. Nature 554(7691):224-228

5. Zuo HL, Di J, Wang T, Guo N (2019) Lateral performance of prestressed diagonal cross-bar reinforced timber shear walls under cyclic loading. J Northeast For Univ 47(06):61-64. https://doi.org/10.13759/j.cnki.dlxb. 2019.06.012 (in Chinese)

6. Mei LD, Guo N, Zuo HL, Li L, Li GD (2021) Influence of the force arm on the flexural performance of prestressed glulam beams. Adv Civil Eng 2021:1-16

7. Tazarv M, Carnahan Z, Wehbe N (2019) Glulam timber bridges for local roads. Eng Struct 188:11-23

8. Buchanan AH, Fairweather RH (1993) Seismic design of glulam structures. Bull N Z Soc Earthq Eng 26(4):415-436

9. Ehrhart T, Steiger R, Palma P, Gehri E, Frangi A (2020) Glulam columns made of European beech timber: compressive strength and stiffness parallel to the grain, buckling resistance and adaptation of the effectivelength method according to Eurocode 5. Mater Struct 53(4):1-12

10. Zuo HL, Li YS, Fu DQ, Guo N (2019) Bending performance test on the different forms of reinforced glulam beams. J Northeast For Univ 47(08):6265. https://doi.org/10.13759/j.cnki.dlxb.2019.08.012 (in Chinese)

11. Yang YL, Liu JW, Xiong GJ (2013) Flexural behavior of wood beams strengthened with HFRP. Constr Build Mater 43:118-124

12. Zhang J, Wang WC, Qiu RG, Shen H, Xu QF, Gao S (2019) Experimental study on short-term flexural behavior of internal prestressed glulam beams. Chin Soc Civil Eng 52(05):23-34

13. Yang HF, Liu WQ, Lu WD, Zhu SJ, Geng QF (2016) Flexural behavior of FRP and steel reinforced glulam beams: experimental and theoretical evaluation. Constr Build Mater 106:550-563

14. Dolan CW, Galloway TL, Tsunemori A (1997) Prestressed glued-laminated timber beam-Pilot study. J Compos Constr 1(1):10-16
15. Frese M, Blass HJ (2009) Bending strength of spruce glulam. Eur J Wood Wood Prod 67(3):277-286

16. Frese M, Enders-Comberg M, Blass HJ, Glos P (2012) Compressive strength of spruce glulam. Eur J Wood Wood Prod 70(6):801-809

17. De Lorenzis L, Scialpi V, La Tegola A (2005) Analytical and experimental Study on bonded-in CFRP bars in glulam timber. Compos B Eng 36(4):279-289

18. Liu W, Yang HF (2008) Experimental study on flexural behavior of engineering wood beams. J Build Struct 29(01):90-95

19. De Luca V, Marano C (2011) Prestressed glulam timbers reinforced with steel bars. Constr Build Mater 30:206-217

20. Guo N, Wang YJ, Zuo HL (2017) Study of short-term flexural behavior for glue-bamboo and lumber beams under different pre-stressed states. Civil Eng J. https://doi.org/10.14311/CEJ.2017.02.0012

21. Guo N, Wang WB, Zuo HL (2019) flexural property of string beam of pre-stressed glulam based on influence of regulation and control. SDHM Struct Durabil Health Monit 13(2):143-179

22. Uzel M, Togay A, Anil O, Sogutlu C (2018) Experimental investigation of flexural behavior of glulam beams reinforced with different bonding surface materials. Constr Build Mater 158:149-163

23. Ribeiro AS, De Jesus AMP, Lima AM, Lousada JLC (2009) Study of strengthening solutions for glued-laminated wood beams of maritime pine wood. Constr Build Mater 23(8):2738-2745

24. Zuo HL, Liu HR, Lu JX (2020) Effect of new self-tapping screw reinforcement measures on bending performance of glulam beams. J Northeast For Univ. 48 (05): 112-116 + 121. https://doi.org/10.13759/j.cnki.dlxb. 2020.05.022. (in Chinese).

25. Yang XH, Xue W, Guo N (2017) Bending performance of glued-lumber beam reinforced with steel plate. J Jilin Univ Eng Technol Ed 2:468-477. https://doi.org/10.13229/j.cnki.jdxbgxb201702017

26. Anshari B, Guan ZW, Kitamori A, Jung K, Komatsu K (2012) Structural behaviour of glued laminated timber beams pre-stressed by compressed wood. Constr Build Mater 29(4):24-32

27. Yang HF, Ju DD, Liu WQ, Lu WD (2016) Prestressed glulam beams reinforced with CFRP bars. Constr Build Mater 109:73-83

28. McConnell E, McPolin D, Taylor S (2014) Post-tensioning of glulam timber with steel tendons. Constr Build Mater 73:426-433

29. Yang YW (2015) The study on flexural performance of prestressed glulam beams string structure based on the creep behavior. Chinese master's thesis, Northeast For Univ. https://kns.cnki.net/kcms/detail/detail.aspx? $\mathrm{dbcode}=C M F D \& d b n a m e=C M F D 201601 \&$ filename $=1015655642 . n h \& v=$ umz5iBe1PfFwRCZQqa\%25mmd2FZ2fz5Og\%25mmd2F8dPamyLA QOFNmCm\%25mmd2Fb4FLbbixMucfer3dMxqhc (in Chinese)

30. GB, T 50329-2012 (2012) Wood construction design standard. China Architecture \& Building Press, Beijing

31. GB, T 228.1-2010 (2010) Metallic materials-tensile testing-part 1: method of test at room temperature. Standards Press of China, Beijing

32. GB, T 50152-2012 (2012) Standard for test method of concrete structures. China Archi-tecture \& Building Press, Beijing

\section{Publisher's Note}

Springer Nature remains neutral with regard to jurisdictional claims in published maps and institutional affiliations. 